\title{
A questão da objetividade nos estudos biográficos de Freud
}

\author{
The question of objectivity in Freud's biographic studies
}

\author{
Marcus Vinicius Neto Silva \\ Guilherme Massara Rocha \\ Universidade Federal de Minas Gerais \\ Brasil
}

\begin{abstract}
Resumo
O problema da objetividade na escrita de uma biografia sempre assombrou os biógrafos. No caso dos estudos biográficos de Freud, essa questão é ainda mais complexa, já que seus primeiros biógrafos eram psicanalistas que tentavam mesclar o método biográfico e o psicanalítico. Discutiremos inicialmente a relação do biógrafo com seu sujeito e o grau de objetividade que é possível atingir ao narrar a vida de alguém. O problema da transferência e das distorções que ela introduz no texto também é abordado. Em seguida acompanharemos os biógrafos de Freud, percorrendo textos desde 1923, para compreender como eles tratam os desafios da relação biógrafo-biografado.
\end{abstract}

Palavras-chave: biografia; Sigmund Freud; metodologia

\begin{abstract}
The problem of objectivity in the writing of a biography has always haunted biographers. In the case of Freud's biographic studies, this question is even more complex, since his first biographers were also psychoanalysts who tried to combine the biographic method with psychoanalysis. We initially discuss the relation of the biographer with his subject and the degree of objectivity that is possible to obtain when one narrates the life of another. The matter of transference and the distortions it introduces in the text is also approached. Next, we follow Freud's biographers, going through texts since 1923 to comprehend how they work with the challenges of the biographer-biographed relation.
\end{abstract}

Keywords: biography; Sigmund Freud; methodology

Freud já foi alvo de um número considerável de estudos biográficos desde o início da década de 1920. Ainda hoje, autoras e autores continuam a se debruçar sobre sua vida e obra, num movimento de repetição e reelaboração constante. Mas se é verdade que há algo em sua trajetória que atrai os pesquisadores de campos variados, é inegável que a profundidade e a qualidade desses estudos variam bastante.

Um problema com o qual todo autor se depara inevitavelmente, quer esteja consciente disso ou não, é relativo ao grau de objetividade de seu relato. A questão é que toda biografia necessita em algum grau de um envolvimento do biógrafo com o biografado. As opiniões divergem com relação ao modo como isso ocorre e como o biógrafo pode se proteger de projeções de seus próprios conteúdos na vida do biografado. 
Mesmo antes de a psicanálise imprimir sua marca no gênero biográfico, já eram comuns as chamadas patografias, que surgem a partir de desdobramentos de pesquisas na área da psicologia científica. Esse tipo de produção tinha como ponto central um estudo psicopatológico de grandes homens. Alguns analistas, como Isidor Sadger, enveredaram por esse campo, com resultados questionáveis. As biografias propriamente psicanalíticas só se tornam comuns a partir de 1910, após a publicação do texto de Freud sobre Leonardo. Na década seguinte este tipo de pesquisa é expandido, e o método psicanalítico começa a ser utilizado com mais frequência, servindo de referência até mesmo para não-analistas (Hoffman, 1984).

Um extenso debate sobre a aplicação da psicanálise às biografias, culminando no uso do termo psicobiografia ${ }^{1}$ para as produções do gênero, ocorre já nesse período inicial. Como Hoffman (1984) aponta, havia quem advogava em favor do uso do método psicanalítico como ferramenta valiosa para explorar a vida de grandes personalidades e também quem apontava que a aplicação de conceitos analíticos era superficial e não produzia uma compreensão maior do biografado, podendo inclusive induzir a interpretações equivocadas.

Entretanto, como afirma Hoffman (1984), "psicobiografias iniciais, apesar de frequentemente não sofisticadas e rudimentares, ao menos abriam possibilidades adicionais para explicações históricas e uma alternativa à idealização biográfica" ( $p$. 349).

\section{O problema da objetividade na escrita biográfica}

O próprio Freud se referiu ao problema das biografias em mais de uma ocasião. Em carta a Arnold Zweig, de 18 de maio de 1936, afirma que "no caso do biógrafo, assim como do psicanalista, encontramos o fenômeno que denominamos 'transferência'" (Freud, 1936/1960, pp. 429-30). Numa outra carta a Zweig, de 8 de outubro de 1936, declara estar alarmado pelo fato de que este autor pretendia escrever uma biografia sua. Esforçando-se para desencorajar o amigo, aponta: "qualquer um que se torne biógrafo compromete-se com mentiras, dissimulação, hipocrisia, lisonjeio e até mesmo ocultação de sua própria falta de compreensão, já que a verdade biográfica não é atingível, e mesmo se fosse, não poderia ser utilizada" (Freud, 1936/1960, p. 430).

Em Uma lembrança de infância de Leonardo da Vinci, Freud (1910/2015) insiste na discussão das dificuldades enfrentadas pelos biógrafos, afirmando:

\footnotetext{
${ }^{1}$ De acordo com Hoffman (1984), o termo foi criado por L. Pierce Clark, psiquiatra norte-americano, que era fortemente influenciado por James Harvey Robinson e Harry Elmer Barnes, adeptos da "Nova História".
} 
biógrafos, de uma maneira muito própria, se fixam em seus heróis. Com frequência, eles os escolheram como seu objeto de estudo, porque eles, devido a sua vida afetiva pessoal, Ihes confrontaram de antemão, com um afeto especial. Eles se dedicam então a um trabalho de idealização, que se esforça em inserir o grande homem no interior de seus modelos infantis, para reviver nele a imagem do pai. Eles apagam esses desejos, preferindo os traços individuais em sua fisionomia, apagam os rastros de sua luta com resistências internas e externas, não toleram neles nenhum resto de fraqueza humana ou imperfeição e nos dão, realmente, uma imagem ideal, fria, estranha em vez de uma pessoa, que poderíamos sentir como um parente distante. Deve-se lamentar que, ao fazer isso, eles sacrificam a verdade por uma ilusão, renunciando, em troca, às suas fantasias infantis e à oportunidade de se ismicuir nos mistérios mais excitantes da natureza humana (p. 153).

Freud parece acreditar que ele próprio talvez não estivesse sujeito a estas limitações. Ao longo de sua vida, escreveu não apenas o texto sobre Leonardo da Vinci, mas explorou também a vida de Moisés, comentou de modo mais breve certos aspectos biográficos de Dostoievski, e escreveu inclusive um artigo autobiográfico. É importante destacar, contudo, a crítica quase unânime ao estudo de Freud sobre da Vinci, acusado de chegar a hipóteses a partir de um erro na tradução de uma das fontes que consultou². Há autores, como Lichtenberg (1978) e Elms (1988), que apontam interferências de fatores da vida do próprio Freud em seu texto, demonstrando exatamente o tipo de perigos a que o biógrafo está sujeito.

Também com relação ao trabalho do historiador (que podemos entender como comparável ao do biógrafo ${ }^{3}$ ), Freud demonstra alguma desconfiança. Em Notas sobre um caso de neurose obsessiva (Freud, 1909/1996a), por exemplo, discute alterações na memória do paciente, uma espécie de reformulação, que seria um processo "perfeitamente análogo ao processo pelo qual uma nação constrói lendas sobre sua história primitiva". Poucas linhas abaixo, afirma que esse mecanismo de alteração faz com que o neurótico apague recordações de certos atos exaltando outros traços de memória, "do mesmo modo como um verdadeiro historiador verá o passado à luz do presente" (Freud, 1909/1996a, p.180).

Mesmo antes dessa data, na reunião de 27 de março de 1907 da Sociedade Psicanalítica de Viena, Freud (citado por Nunberg \& Federn, 1962) afirma que "devemos nos precaver contra aceitar as declarações dos pacientes como material científico inteiramente válido (...), já que apresentam uma imagem falsificada,

\footnotetext{
${ }^{2}$ Ver, por exemplo, Lichtenberg (1978) e Caine (2010).

3 Meyers (1989) elenca diversos autores que defendem uma completa identidade entre história e biografia, como Yeats, Emerson, Auden, Eliot e Froude. Emerson (2001), por exemplo, afirma que "não há propriamente história, apenas biografia" (p. 9). Yeats (citado por Meyers, 1989), declara: "nada existe, a não ser uma corrente de almas, (...) todo conhecimento é biografia" (p. 4).
} 
composta de fantasia e realidade". Ele completa, apontando que "a fantasia preenche lacunas de memória de uma forma plausível e geralmente engenhosa". E conclui que "pessoas normais, também, projetam suas fantasias no passado. (...) O historiador procede de modo similar quando projeta a visão de sua época no passado" (p. 156).

$\mathrm{Na}$ visão de Freud, portanto, parece que o historiador e o biógrafo estão condenados a contaminar seu trabalho com fantasias e idealizações, projetadas no conteúdo daquilo que escrevem. Curiosamente, Freud caracteriza também o trabalho do escritor de maneira semelhante. A criação literária carrega a marca das fantasias e sonhos diurnos de seu autor, apresentadas de forma ligeiramente distorcida. Não seria absurdo, portanto, pensar que existe um parentesco entre a biografia e uma obra literária, afinal de contas (Freud, 1908/2015).

O biógrafo, portanto, trabalha nesse delicado intervalo entre fantasia e realidade, entre uma escrita objetiva e subjetiva, ou, como indica Dosse (2009), "o biógrafo é livre para escolher seu estilo e dosar seu tom entre a escrita romanesca e a escrita histórica. (...) O gênero biográfico ressalta a diferença entre identidade propriamente literária e identidade científica" (p. 68). Edel (1978) aponta que "é permitido ao biógrafo ser tão imaginativo quanto deseje, desde que ele não imagine seus fatos". (p.1) Ele completa, afirmando: "O biógrafo é um artista a partir do momento em que ele escolhe entre diferentes conjuntos de fatos e justifica o que ele escolheu" (p. 2).

Dosse (2009) afirma que uma biografia leva ao extremo os polos de sua escrita: o autor, o narrador e a personagem. Em sua visão, o biógrafo (assim como o historiador) "ficcionaliza seu objeto e torna-o, por isso mesmo, inalcançável, apesar do efeito do vivido que com isso obtém" (p. 71). A questão, portanto, é que no gênero biográfico os aspectos factuais se relacionam de forma complexa com o caráter ficcional da obra. Caberá ao biógrafo expor "as motivações que o levaram a acompanhar a vida do biografado e retraçar-lhe a carreira" (Dosse, 2009, p. 95).

Ao fazer isso, prossegue Dosse (2009), ele "revela seus objetivos, suas fontes e seu método, elaborando assim uma espécie de contrato de leitura com o leitor" ( $p$. 95). Nesse sentido, a biografia teria de ser definida como um "relato no qual o narrador se ausenta da história que conta", apesar da ressalva de que ela não é "escrita a partir de uma exterioridade total" (p. 95).

Por esse motivo, Dosse (2009) cita Lejeune para concluir que uma das maiores contradições inerentes à escrita biográfica "se situa entre a ambição de objetividade e a postura real do biógrafo" (p. 96). Assim, "a relação biográfica conserva sempre certa ambivalência e o biógrafo surge ao mesmo tempo como embalsamador potencial e coveiro" (p. 114). Como forma de moderar essa ambivalência e escapar de seus perigos, Dosse (2009) afirma: "Alain Buisine defende a ideia segundo a qual não 
existe um método único para redigir a biografia de um autor: 'Para cada escritor é preciso inventar uma forma nova e específica de biografia'"' (p. 309).

Pensando exatamente nessa posição do biógrafo, Young-Bruehl (1998) propõe a necessidade de uma relação de empatia entre o biógrafo e seu sujeito. Entretanto, a autora não acredita que empatia seja "colocar-se no lugar do outro", mas "empatia envolve, ao contrário, colocar outro em si, se tornar o habitat de outra pessoa, (...) mas sem dissolver a pessoa, sem digeri-la" (Young-Bruehl, 1998, p. 22).

Hitschmann (1956) é taxativo com relação à sua prescrição de que apenas analistas seriam capazes de escrever biografias de forma competente. Entretanto, ele alerta que "o que quer que você escreva, você escreve apenas sobre si mesmo mesmo quando escreve biografias de outros" (p. 269).

Elms (1994) argumenta em favor de o biógrafo escolher um sujeito com o qual tenha uma relação de forte ambivalência, para que isso proteja o biógrafo de uma postura de idealização. Na visão do autor, os fortes sentimentos positivos serão contrabalançados pelos negativos, resultando numa narrativa mais objetiva. Ele recomenda ainda que seria útil aos biógrafos submeter-se à análise, para manter a ambivalência sob controle. "Contudo, o campo dos estudos biográficos de Freud está repleto de trabalhos de psicanalistas que presumivelmente foram completamente analisados, mas que (como Ernest Jones) permanecem incapazes de controlar sua forte transferência positiva ou negativa com relação ao velho" (p. 20).

O tema da transferência e contratransferência surge insistentemente nas discussões de diversos autores. Gedo (1972) afirma que "o mais difícil problema metodológico da biografia é a questão da transferência" (pp. 644-5). Edel (1984) também parece concordar, e declara que a "'transferência' está no centro de toda escrita biográfica, mas os biógrafos resistem a essa concepção de seu trabalho" ( $p$. 284).

Schepeler (1990) debate detalhadamente a questão da transferência do biógrafo e propõe que ele deve se valer de algumas estratégias para lidar com ela. Primeiramente, o biógrafo deve se interrogar sobre o motivo da escolha de determinado sujeito para ser biografado. Em segundo lugar, a autora indica três formas de se proteger de uma escrita dominada pela transferência: colaboração do biógrafo com um psicanalista, autoanálise e discussão dos resultados parciais com colegas críticos. Outra saída interessante levantada por Schepeler é a inclusão de um texto pelo próprio biógrafo, discutindo sua relação transferencial com o biografado.

Um exemplo interessante desse "contrato de leitura", para usar a expressão de Dosse (2009), aparece no estudo biográfico escrito por Freud e Bullitt (1966/1984) sobre Wilson. Na introdução desse livro, escrita por Freud, ele declara: 
Devo porém, iniciar minha contribuição a este estudo psicológico de Thomas Woodrow Wilson confessando que a figura do presidente americano, ao despontar no cenário europeu, foi-me antipática desde o começo, e que esta aversão só fez crescer à medida que, com o passar do tempo, vim a saber mais dele (p. 18).

Não muito adiante descreve como eventualmente veio a sentir certa simpatia por Wilson, mas esse afeto logo veio a ser suplantado por outro, a comiseração, que dominou toda a sua escrita. Mesmo assim, Freud se dirige ao leitor e pede que "não rejeite o presente trabalho como produto de preconceito. Embora não tenha nascido isento de sentimentos fortes, estes sentimentos foram totalmente subjugados" (Freud \& Bullitt, 1966/1984, p. 20).

A questão, então, é de que forma o biógrafo pode se proteger das distorções causadas pela sua relação afetiva com seu sujeito. Anderson (1981) aponta que "o reconhecimento da contratransferência e o desenvolvimento da empatia são as duas técnicas mais adequadas para proteger contra a tendência a ser depreciativo" ( $p$. 465). Ele indica o estudo de Freud sobre Wilson como um exemplo de como é difícil para um biógrafo se defender de seus conteúdos internos, que provocam distorções consideráveis no seu retrato do biografado.

Anderson (1981) resume sua abordagem a uma combinação de estratégias que envolvem imersão no material que serve de fonte, desenvolvimento de uma relação empática com o sujeito e sempre chocar as hipóteses com os dados disponíveis.

Edel (1961) propõe que

o biógrafo deve tentar se conhecer antes de tentar conhecer a vida de outra pessoa. Auto-conhecimento, como sabemos, é raramente completamente alcançado. E nosso dilema é que para escrever uma boa biografia, devemos nos identificar com nosso sujeito em algum grau; de que forma re-experimentamos seus sentimentos, seus problemas, suas lutas? Devemos tentar medir o mundo através dos olhos do sujeito e penetrar nesse mundo. Mas ao nos tornarmos essa outra pessoa para os propósitos da biografia, o biógrafo arrisca tudo. (...) Ele deve ser compreensivo porém reservado, envolvido e não envolvido. Esse é o coração de sua tarefa (p. 461).

Edel (1961) conclui que "o melhor (...) que o biógrafo orientado analiticamente pode fazer é cultivar sua consciência de tais questões e reconhecer a ameaça constante que elas representam à sua objetividade. Assim ele pode trabalhar um pouco menos cegamente e de forma menos ignorante" (p. 461). A solução de Edel, portanto, não é completa, e obriga o biógrafo a uma reavaliação constante de si mesmo. 
Tentaremos, a seguir, observar de que modo os biógrafos de Freud enfrentaram estas questões e que soluções encontraram. Será possível notar que há uma variação considerável com relação ao grau de objetividade que cada um foi capaz de obter, bem como diferenças enormes na abordagem para lidar com tais dificuldades.

\section{Os estudos biográficos sobre Freud}

Desde o início, os autores que se esforçaram para construir biografias de Freud se depararam com desafios e problemas. Porém, isso não parece ter inibido muitos deles, já que o número de biografias escritas sobre o fundador da psicanálise provavelmente atinge a casa das centenas. Biografar Freud é uma tarefa complexa e aqueles que pretenderam realizá-la ao longo dos anos tentaram expor de modo mais ou menos claro quais foram suas intenções, quais os impasses enfrentados e que tipo de soluções encontraram.

Tentaremos seguir os passos de alguns deles. Para isso, tomaremos como fonte trabalhos distribuídos entre 1924 e 2017, de autores de diferentes nacionalidades e formações. Essa seleção pode parecer arbitrária, mas almejamos apresentar um panorama geral das produções nesse campo, destacando obras que tiveram maior impacto sobre a produção posterior ou que são exemplares de uma determinada abordagem. Manteremos o foco na parte inicial de cada livro, nos prefácios ou prólogos, em que o autor apresenta as questões e as justificativas de sua pesquisa.

A primeira biografia de Freud que analisaremos foi escrita em 1923 e traduzida para o inglês no ano seguinte: Sigmund Freud: his personality, his teaching and his school, de autoria de Fritz Wittels (1924). Wittels, que havia participado da Sociedade Psicanalítica de Viena até 1910, quando foi afastado, decide escrever essa obra com Freud ainda vivo. No início de seu livro, declara que, apesar disso: "nos anos de 1905 a 1910 meu relacionamento com esse grande homem era suficientemente íntimo para justificar minha escrita de sua biografia" (Wittels, 1924, p. 7). E completa: "Meu distanciamento de Freud desde 1910, meu desapego de sua individualidade ofuscante talvez seja uma vantagem. Discípulos acríticos ele tem mais que o suficiente, eu gostaria de ser uma testemunha crítica" (p. 7).

A questão que surge para Wittels (1924) é principalmente o grau de objetividade que ele conseguiria alcançar em seu relato. A maior parte do que ele narra provém de fatos que ele próprio testemunhou; aquilo que ele próprio não observou é complementado pelo relato de outras pessoas. Não é um livro que se baseia em larga documentação dos fatos, até porque tal documentação não estava acessível naquele período. Freud, que ainda contava com 63 anos de idade nessa ocasião, leu a cópia que lhe fora enviada e respondeu com alguns comentários ao autor. Apesar de crítico 
com relação a toda essa empreitada, tece alguns elogios ao esforço de Wittels. Entretanto, alerta: "Sua distância pessoal em relação a mim, que o sr. avalia como pura vantagem, tem também grandes desvantagens. O sr. sabe pouco sobre seu objeto, e por isso não pode evitar o risco de tratá-lo grosseiramente" (Freud, 19234/2011, p. 344). Ele ainda aponta que Wittels possivelmente atribui a ele características que não possui, e que isso resulta num retrato por vezes idealizado, mas que no fim das contas parece contraditório.

Wittels, portanto, parece encurralado por duas grandes dificuldades: acesso a pouco material, o que o obrigava a fazer muitas suposições baseado em informações parciais, e sua relação complexa com Freud, que de algum modo comprometia a objetividade de sua abordagem, apesar de ele próprio acreditar no contrário.

Sadger (1930/2005) inicia seu livro, Recollecting Freud, com a afirmação de que pretende "mostrar a totalidade de Freud em toda sua genialidade extraordinária, bem como em seus erros" (p. 5). Entretanto, ele faz uma advertência:

Os capítulos seguintes contêm nada mais do que aquilo que experienciei pessoalmente, e as impressões que o caráter de Freud, suas ações e escritos tiveram em mim. Em nenhum momento procurei apresentar detalhes biográficos que eu mesmo não tenha testemunhado (p. 5).

Com essas afirmações, ele tenta delimitar bem o alcance do que apresentará ao longo do livro, alimentado por uma preocupação de que os críticos de Freud pudessem usar suas observações como munição contra ele. Sadger parece ciente de que seu relato é parcial, e ao marcar isso, informa ao leitor que não está observando Freud por todos os ângulos e que, portanto, não é possível tomar suas declarações como a verdade sobre seu mestre.

Um outro livro, também publicado por um discípulo de Freud, tenta resolver essa questão de outra forma. Sigmund Freud: master and friend, de Hanns Sachs (1944), "não pretende ser uma biografia completa", já que "para realizar essa tarefa seriam necessárias várias coisas que não estão a minha disposição, entre elas o desejo de empreendê-la" (p. 3). Segundo ele: "em certo sentido, esse livro poderia ser visto como uma parte de minha autobiografia" ( $p .3$ ). Sua justificativa para escrever o livro era de que "certo dia (...) olhei em volta e me tornei ciente de que dentre os que formavam seu círculo íntimo de discípulos e que tiveram oportunidade de viver por muitos anos próximos a sua residência (...), eu era o único sobrevivente" (pp. 4-5).

O que temos aqui, portanto, é muito menos uma biografia, mas uma espécie de livro de memórias. O autor não apenas não disfarça o fato, mas o expressa nos seguintes termos: "Meu livro não é baseado em pesquisa. Não tenta abrir nenhuma perspectiva histórica. Ele conta o que aconteceu diante de meus olhos e descreve de 
que modo isso ficou impresso em minha memória" (Sachs, 1944, p. 5). Sachs indica que "a primeira dúvida a ser analisada é minha completa falta de objetividade, que professo aberta e alegremente. (...) Nunca pensei em Freud como um 'objeto' e não pretendo começar a fazer isso agora" (p. 5). Ele se interroga se essa confissão significará que tudo que relatar será descartado como sendo não confiável, apenas o relato de um entusiasta acrítico. Sua saída é um tanto desconcertante. Ele afirma acreditar que a idealização genuína auxilia, e não prejudica, um relato desse tipo. Em sua opinião, "a mente do biógrafo está tão preenchida por seu sujeito que suas palavras fluem sem restrição como uma nascente nas montanhas" (p. 9).

Para Sachs (1944), portanto, a falta de objetividade não parece configurar um problema, nem tornar seu relato digno de desconfiança, já que, para ele, "subjetividade não é o mesmo que falsificação" (p. 9).

Porém, alguns anos depois, em 1947, começam a surgir biografias escritas por autores externos ao movimento psicanalítico. Uma dessas obras é Freud desmascarado, de Emil Ludwig (1948), jornalista polonês que emigrou para os Estados Unidos em 1940. Esse autor, claramente contrário à psicanálise e a Freud, afirma que sua intenção ao escrever a biografia é denunciar os excessos de Freud e os perigos da psicanálise. Em sua visão, Freud, com suas teorias, acabava por "alimentar ilusões nos espíritos mais débeis", colocando em risco "a imaginação das multidões, exagerando os fatores sexuais" (p. 54). De acordo com ele, "Freud ensinou a justificar todas as fraquezas como enfermidades interessantes e a deixar de lado a saúde, a beleza, o amor e as banalidades normais" (p. 56). Ao longo da obra também fica claro que ele não faz uma apresentação biográfica completa e se ocupa mais em atacar as teorias freudianas, seu caráter e seus supostos efeitos nocivos. Ludwig não parece se questionar em momento algum sobre a legitimidade de seu empreendimento. Suas alegações e conclusões, escritas num período em que o acesso a documentos era ainda bastante restrito, sofrem das mesmas limitações que as biografias anteriores. Entretanto, se Sachs era capaz de enxergar sua falta de objetividade e Wittels se julgava distante o bastante para apresentar uma descrição menos distorcida de Freud, Ludwig sequer levanta a possibilidade de que sua leitura possa ser parcial. Ele apresenta o contrário de uma versão idealizada e ajuda a implantar todo um campo que floresceu posteriormente, de biografias difamatórias de Freud (Freud-bashing).

De toda forma, seu livro (junto com outros da mesma safra ${ }^{4}$ ), levantam um problema: seria possível um autor não psicanalista apresentar um retrato fiel de Freud, que fosse capaz de apreciar também o desenvolvimento da psicanálise? Uma das respostas imediatas a essa tendência foi o surgimento da biografia escrita por

\footnotetext{
${ }^{4}$ Outra biografia escrita com tom semelhante e publicada também em 1947 é Freud: his life and his mind, de Helen Puner (1947/1959).
} 
Ernest Jones, publicada em três volumes ao longo da década de 1950 (o primeiro em 1953, o segundo em 1955 e o terceiro em 1957). "Essa não pretende ser uma biografia popular de Freud: muitas já foram escritas, contendo sérias distorções e inverdades" (Jones, 1953, p. xi). Assim Jones inicia sua apresentação, para destacar em seguida que os objetivos do livro são narrar os principais fatos da vida de Freud, mas também estabelecer relações entre as experiências de sua vida e o desenvolvimento de sua obra.

Segundo Jones (1953), a família de Freud sempre respeitou o desejo dele por privacidade e não pretendia apoiar um projeto desse tipo, mas pessoas de má-fé já se davam ao trabalho de distorcer passagens de seus textos: "notícias de estórias falsas inventadas por pessoas que nunca o haviam conhecido, estórias que gradualmente se acumulavam formando uma lenda mentirosa" (p. xi). Assim, Jones conseguiu angariar o apoio da família para retificar a situação.

Jones (1953) também discute a tarefa complexa que é escrever uma biografia de alguém como Freud. De acordo com ele, o volume de dados era tão grande, que ele só pôde apresentar uma seleção do material. Ele afirma que apenas se sentiu compelido a aceitar a tarefa por ser o único sobrevivente do círculo mais íntimo de Freud, de quem foi amigo por quarenta anos. Ele aponta como credenciais o fato de ter tido uma formação semelhante a de Freud, além de ser o único estrangeiro naquele círculo, o que deu a ele "uma oportunidade para algum grau de objetividade maior que dos outros" (p. xiii). E completa: "minha propensão a adoração de heróis tinha sido resolvida antes mesmo de tê-lo encontrado" (p. xiii).

De fato, Jones foi o primeiro autor a ter realmente que se preocupar com o excesso de material, o que desloca o problema em certa medida. A questão não era simplesmente saber se ele era capaz de fornecer interpretações isentas ou produzir especulações exageradas. O problema agora diria respeito à seleção que ele fez desse material. Como ninguém tinha acesso às mesmas fontes no período, não havia nenhuma maneira de descobrir o que ele havia deixado de fora. Mesmo assim, nos anos imediatamente seguintes, alguns autores se insurgiram contra pontos específicos de sua narrativa, especialmente Balint, que discordava da forma como Ferenczi havia sido apresentado, e Bettelheim (1991), que achava que o Freud de Jones era uma versão altamente distorcida. O verdadeiro problema de Jones talvez não fosse o de ser ou não suficientemente objetivo, mas como sê-lo, quando sua produção era acompanhada de perto pelos herdeiros da família, especialmente Anna Freud. Olhando por esse viés, Jones tinha de combater não apenas suas próprias forças internas que poderiam produzir distorções, mas a pressão da família por um Freud aceitável, passível de ser mostrado ao público, e que pudesse fazer frente aos ataques que ele vinha sofrendo. 
No ano de 1972 surge outra obra, escrita por Max Schur (1972), médico de Freud, Freud: living and dying. Ele declara, no prefácio do livro, que seu trabalho, "apesar de ser um estudo biográfico, não é uma biografia em larga escala" (p. 16). Schur (1972) alega ter resistido à ideia de escrever um livro sobre Freud. Sua proposta parece semelhante a de biógrafos anteriores, mas se diferencia deles ao afirmar que fazia isso não por respeito à privacidade, mas porque sabia que tinha de se "distanciar para poder adquirir a objetividade necessária" ( $p$. 2-3). O problema, para o autor, é que nenhum estudo biográfico escrito por um psicanalista pode prescindir de aplicar psicanálise a seu objeto. A questão aqui, então, é como realizar esse esforço de análise e conjugar os materiais disponíveis em interpretações que sejam plausíveis. Se Jones oscilava entre analisar Freud e atender a interesses da família, Schur alterna entre isso e atender a um ideal pessoal: "Eu teria de abordar o tópico de um modo que seria aceitável ao próprio Freud" (p. 3).

Já no final da década de 1970, surge Freud: biologist of the mind. Seu autor, Frank J. Sulloway (1979), apresenta seu trabalho da seguinte maneira: "esta é uma biografia intelectual com uma tese específica. A imagem central é de que Freud, ao longo dos anos, se tornou um cripto-biólogo, ou um biólogo encoberto" (p. 3). De acordo com ele, para chegarmos a essa visão de Freud como "psicobiólogo" (outro dos termos que ele utiliza para defini-lo), seria necessário desenredar fatos históricos e ficção, o que havia ocorrido até a presente data. Sua proposta, portanto, seria apresentar um Freud que teria permanecido desconhecido e incompreendido, devido a distorções de biógrafos anteriores. Ele não apresenta, porém, uma crítica de como sua própria apresentação da figura de Freud poderia ter sido influenciada por esse seu projeto de demonstrar que o autor era uma espécie de biólogo disfarçado.

Com a biografia escrita por Peter Gay em 1988, temos agora um historiador abordando a vida de Freud. O autor não conheceu Freud, não tinha relações diretas com sua família, o que o colocava numa posição inicialmente mais isenta. A essa altura já havia também uma quantidade considerável de material publicado sobre Freud: coletâneas de cartas, relatos de ex-pacientes, etc. Sua dificuldade era, em certa medida, justificar a existência de seu livro diante de uma já extensa tradição. Gay (1988/2012) afirma: "Não escrevi esse livro para lisonjear nem para denunciar, mas para compreender. No texto propriamente dito não discuto com ninguém" ( $p$. 17). Declara ter se valido dos métodos psicanalíticos na exploração da vida de Freud, mas de maneira moderada. Sua obra parece planejada para trazer ao público leigo contemporâneo uma versão da vida de Freud e, ao mesmo tempo, atender aos estudiosos do campo, motivo pelo qual ele inclui um ensaio bibliográfico ao final, com detalhes sobre as obras consultadas ao longo de todo o livro. 
Dentre todas as biografias, talvez a escrita por Emilio Rodrigué (1995), Sigmund Freud: o século da psicanálise seja a mais peculiar. No prólogo, o autor logo levanta o problema de que "para um psicanalista, historizar Freud significa futucar Freud, deitálo no divã" (p. 26). Mas ele não propõe simplesmente aplicar o instrumental psicanalítico para narrar a vida de Freud. Nas palavras de Rodrigué: "minha apreciação percorre um leque abrangendo desde o escárnio à hagiografia. Eclético na medida em que aceito a maré transferencial que esteja me levando" (p. 27).

Ele levanta um problema que não aparece claramente em nenhuma outra biografia: deve-se considerar o contexto geográfico e histórico não apenas do biografado, mas do biógrafo. Sua biografia carregaria a marca da América Latina, em oposição às biografias anteriores, europeias e estadunidenses. Ele também não está alheio ao perigo da idealização que assolou diversas biografias anteriores. Afirma: "à diferença da história, a biografia é um empreendimento essencialmente identificatório. Com efeito, a biografia é a arte de ser o outro" (Rodrigué, 1995, p. 35). Mas não basta notar isso, seria preciso "ir dando passos invisíveis, quase impossíveis, e pular fora da transferência de discípulo" (p. 35).

O empreendimento de Rodrigué (1995), portanto, parece algo que fica no meio do caminho entre uma biografia de Freud e uma tentativa do autor de se desembaraçar dos laços transferenciais que o mantinham ligado a Freud.

Em 2014 surge uma biografia publicada por um autor britânico, Adam Philips. Para ele, "a estória ${ }^{5}$ da vida de Freud é facilmente narrada" (Philips, 2014, p. 1). Entretanto, o autor desconfia dessa facilidade, apontando que "depois da psicanálise, todas a nossas narrativas do passado - de fato, toda nossa coerência e plausibilidade - são suspeitas" (p. 6). De acordo com ele, "o psicanalista é um historiador que nos mostra que nossas histórias são também uma forma de ocultar o passado de nós mesmos" (p. 7).

Assim, o conhecimento que podemos obter sobre a vida de qualquer pessoa "deve ser temperado com uma certa ironia" (Philips, 2014, p. 11). Numa posição que pareceria contraditória para um biógrafo, declara: "uma biografia, como um sintoma, fixa uma pessoa em uma história sobre ela mesma" (p. 16). Seria preciso, então, que "nos curássemos do desejo por biografia, e nossa crença nela" (p. 21). A crítica de Philips parece dirigida à linearidade e simplificação que toda biografia acaba produzindo, bem como a suposta intenção de revelar a verdade sobre uma vida. Que ele ainda assim deseje escrever uma biografia de Freud apenas acrescenta peso à ironia que permeia sua escrita.

\footnotetext{
${ }^{5}$ Philips (2014) oscila entre o uso do termo story e history, aproximando os dois sentidos ao propor o caráter ficcional de toda história.
} 
Outra historiadora que também resolve escrever uma biografia de Freud é Elisabeth Roudinesco. Ela expressa abertamente o fato de que o pesquisador atual "vê-se confrontado com um excesso de arquivos e, consequentemente, com uma pluralidade infinita de interpretações" (Roudinesco, 2016, p. 9). Suas razões para escrever esse livro são curiosamente muito semelhantes às apresentadas por Jones:

Após décadas de panegíricos, hostilidades, trabalhos eruditos, interpretações inovadoras e declarações injustas (...) é grande a dificuldade de saber quem era realmente Freud, de tal forma o acúmulo de comentários, fantasias, lendas e rumores terminou por encobrir o que foi o destino paradoxal desse pensador na sua época e em nosso tempo (Roudinesco, 2016, pp. 10-1).

Ela insiste na ideia de que com a abertura dos arquivos quase em sua totalidade era agora possível acessar a vida de Freud de um modo nunca antes realizado, e com isso desfazer algumas interpretações equivocadas ou fantasiosas. De toda forma, sua narrativa se afasta muito pouco das anteriores, e parece planejada principalmente para seu público francês, que a autora parece considerar como tendo pouco interesse e conhecimento sobre Freud e seu lugar na história.

Por último, temos dois livros lançados este ano, 2017. O primeiro deles escrito por Joel Whitebook (2017): Freud: an intelectual biography. O autor abre a obra com a pergunta: "O mundo precisa de outra biografia de Sigmund Freud? A resposta é um enfático $\operatorname{sim}^{\prime \prime}$ (p. 1). Ele crê que os avanços nos estudos sobre Freud, aliados a desenvolvimentos posteriores da teoria psicanalítica e as críticas sofridas pela psicanálise a partir do movimento feminista permitem construir hoje uma biografia que não teria sido possível noutro momento. Entretanto, ele pretende centrar seu livro em dois pontos: a mãe ausente (na teoria e na vida de Freud) e a ruptura com a tradição. Whitebook aponta que uma biografia detalhada seria um esforço redundante, já que há um grande número delas, e insiste na ideia de que hoje já estamos distantes o suficiente de Freud para conseguirmos formar uma imagem mais madura, menos idealizada dele.

Entretanto, talvez Whitebook (2017) estivesse sendo muito otimista, já que os estudos biográficos de Freud, especialmente nos Estados Unidos, ainda carregavam a marca das produções difamatórias. Um dos últimos esforços nesse sentido é o livro recém-publicado de Crews (2017), Freud: the making of an illusion. Ele também inicia sua obra interrogando sobre a justificativa para uma biografia de Freud, que já tinha sido suficientemente estudado. Em sua opinião, seu livro se justificaria devido ao objetivo explícito de desconstruir os efeitos do que ele chama de apaixonamento em massa pela figura de Freud. 
O esforço de Crews (2017) é prejudicado por parecer já conter a resposta antes mesmo de realizar a pesquisa. Para ele, o desejo de Freud pela fama a qualquer custo é o que explicaria seu percurso. As reviravoltas na vida de Freud seriam nada mais do que reajustes e dissimulações realizadas por ele para que pudesse atingir seu objetivo final de obter reconhecimento. Crews parece crer que, tendo participado do movimento psicanalítico e depois se afastado, sua abordagem é mais isenta do que a dos que permanecem discípulos de Freud. Ele não nos apresenta mais argumentos sobre porque seria mais capaz do que os biógrafos anteriores, que critica duramente. Ao que tudo indica, ele padece do mesmo problema de vários outros: idealização do biografado, embora aqui dominada por uma transferência negativa.

\section{Considerações finais}

Notamos, portanto, que as principais dificuldades enfrentadas pelos biógrafos de Freud dizem respeito ao acesso a documentos, a objetividade, e à aplicabilidade da psicanálise como método ao relatar a vida de Freud. No primeiro dos casos, a situação dos primeiros biógrafos era dramática: não se tinha quase nenhum material à disposição e era preciso recorrer quase exclusivamente a relatos de testemunhas, nem sempre confiáveis. A questão da objetividade permeia todas as obras. Se inicialmente era difícil manter uma distância, já que os primeiros biógrafos eram discípulos ou ex-discípulos, envolvidos em relações complexas com seu objeto, é difícil saber se nossa distância de Freud tornou mais fácil esse trabalho. Vemos claramente que mesmo autores atuais frequentemente apresentam um Freud altamente idealizado. Parece que essa questão se atualiza em cada nova geração. Por último, temos a dificuldade que surge da possibilidade de aplicar a psicanálise a Freud. Aqui temos um problema metodológico que divide opiniões. Se é inegável que é possível dar algum tratamento analítico a material semelhante (o próprio Freud recorreu a essa estratégia em mais de uma ocasião), é difícil saber até onde o material disponível nos autoriza a ir. Como aponta Gedo (1972), "o problema metodológico crucial da biografia analítica pode muito bem ser que tipo de material aceitamos como um substituto para as associações livres" (p. 641). É preciso prosseguir com cuidado extremo, e talvez seja interessante lembrar da recomendação que Freud faz a Wittels em 1923: "o que parece verdadeiro nem sempre é verdade" (Freud, 1923-4/1996b, p. 321).

Mesmo assim, uma das contribuições mais interessantes da teoria psicanalítica para os estudos biográficos reside no esforço para esclarecer os complexos laços afetivos estabelecidos entre o biógrafo e seu sujeito. Aqui os métodos utilizados pelos biógrafos para se defender de uma tendência a distorcer o material a partir das 
próprias fantasias diferem bastante. Temos aqueles como Hitschmann (1956) que creem que "apenas um analista é competente e qualificado para escrever as biografias de grandes homens" (p. 269). Mas há também os mais moderados, como Edel (1961, 1978), Anderson (1981) e Young-Bruehl (1998) que advogam em favor de uma abordagem que preza pela auto-observação, sem negar a necessidade de estabelecer uma relação empática com seu sujeito. Independente do caminho escolhido, é necessário reconhecer, como Novak (1989), que "não há algo como um biógrafo invisível" (p. 38). Concordamos com o autor que "no lugar de ambicionar uma objetividade ilusória" o biógrafo deveria "admitir sua presença na obra e oferecer seus julgamentos tão honestamente quanto possível" (p. 38).

No caso das biografias de Freud, os diversos autores encontraram seus caminhos impedidos pelos mais variados motivos: proximidade demais do biografado, pouca proximidade com ele, atuação intensa de fatores transferenciais, positivos e negativos, e dificuldade em localizar quando está forçando na narrativa seus próprios conteúdos. Entretanto, a solução proposta por alguns de que uma biografia isenta só fosse possível de ser escrita por um analista (supostamente alguém analisado e com domínio suficiente de seus mecanismos de defesa) não parece garantir muita coisa, já que grande parte dos estudos biográficos de Freud foram escritos por psicanalistas, e variam enormemente em relação ao grau de distorção introduzido.

\section{Referências}

Anderson, J. W. (1981). The methodology of psychological biography. The Journal of Interdisciplinary History, 11(3), 455-475.

Bettelheim, B. (1991). Duas visões de Freud. Em B. Bettelheim. A Viena de Freud e outros ensaios (pp. 37-53). (L. Wyler, Trad.). Rio de Janeiro: Campus. (Original publicado em 1990).

Caine, B. (2010). Biography and history. London: Palgrave Macmillan.

Crews, F. (2017). Freud: the making of an illusion. New York: Metropolitan Books.

Dosse, F. (2009). O desafio biográfico: escrever uma vida (G. C. C. Souza, Trad.). São Paulo: Edusp. (Original publicado em 2005).

Edel, L. (1961). The biographer and psycho-analysis. International Journal of Psychoanalysis, 42, 458-466.

Edel, L. (1978). Biography: a manifesto. Biography, 1(1), 1-3.

Edel, L. (1984). Transference: the biographer's dilemma. Biography, 7(4), 283-291. 
Elms, A. C. (1988). Freud as Leonardo: why the first psychobiography went wrong. Journal of Personality, 56(1), 19-40.

Elms, A. C. (1994). Uncovering lives: the uneasy alliance of biography and psychology. New York: Oxford University.

Emerson, R. W. (2001). History. Em R. W. Emerson. Essays (pp. 5-25). Hazleton: Pennsylvania State University.

Freud, E. (1960). The letters of Sigmund Freud. New York: Basic Books.

Freud, S. (1996a). Análise de uma fobia em um menino de cinco anos. Em S. Freud. Edição standard brasileira das obras psicológicas completas de Sigmund Freud (Vol. X; pp. 13-133). (J. Salomão, Trad.). Rio de Janeiro: Imago. (Original publicado em 1909).

Freud, S. (1996b). Carta a Fritz Wittels. Em S. Freud. Edição standard brasileira das obras psicológicas completas de Sigmund Freud (Vol. XIX; pp. 320-321). (J. Salomão, Trad.). Rio de Janeiro: Imago. (Original publicado em 1923-4).

Freud, S. (2011). Carta a Fritz Wittels. Em S. Freud. O eu e o id, autobiografia e outros textos (pp. 344-345). (P. C. Souza, Trad.). São Paulo: Companhia das Letras. (Original publicado em 1923-4).

Freud, S. (2015). O poeta e o fantasiar. Em S. Freud. Arte, literatura e os artistas (pp. 53-66). Belo Horizonte: Autêntica. (Original publicado em 1908).

Freud, S. (2015). Uma lembrança de infância de Leonardo da Vinci. Em S. Freud. Arte, literatura e os artistas (pp. 69-165). Belo Horizonte: Autêntica. (Original publicado em 1910).

Freud, S. \& Bullitt, W. (1984). Thomas Woodrow Wilson: um estudo psicológico (H. L. Barros, Trad.). Rio de Janeiro: Graal. (Original publicado postumamente em 1966).

Gay, P. (2012). Freud: uma vida para o nosso tempo (D. Bottmann, Trad.). São Paulo: Companhia das Letras. (Original publicado em 1988).

Gedo, J. (1972). The methodology of psychoanalytic biography. Journal of the American Psychoanalytic Association, 20(3), 638-649.

Hitschmann, E. (1956). Some psycho-analytic aspects of biography. International Journal of Psycho-Analysis, 37, 265-269.

Hoffman, L. (1984). Early psychobiography, 1900-1930: some reconsiderations. Biography, 7(4), 341-351. 
Jones, E. (1953). The life and work of Sigmund Freud. New York: Basic Books.

Lichtenberg, J. (1978). Freud's Leonardo: psychobiography and autobiography of genius. Journal of the American Psychoanalytic Association, 26, 863-880.

Ludwig, E. (1948). Freud desmascarado (A. Andrade, Trad.). Rio de Janeiro: José Olympio. (Original publicado em 1946).

Meyers, J. (1989). Introduction. Em J. Meyers (Org.). The biographer's art (pp. 1-9). London: Macmillan.

Novak, M. (1989). James Boswell's Life of Johnson. Em J. Meyers (Org.). The biographer's art (pp. 31-52). London: Macmillan.

Nunberg, H. \& Federn, E. (1962). Minutes of the Vienna Psychoanalytic Society (Vol. 1). New York: International Universities.

Phillips, A. (2014). Becoming Freud. New Haven: Yale University.

Puner, H. W. (1947/1959). Freud: his life and his mind. New York: Dell.

Rodrigué, E. (1995). Sigmund Freud: o século da psicanálise. São Paulo: Escuta.

Roudinesco, E. (2016). Sigmund Freud: na sua época e em nosso tempo (A. Telles, Trad.). Rio de Janeiro: Zahar. (Original publicado em 2014).

Sachs, H. (1944). Freud, master and friend. Cambridge: Harvard University.

Sadger, I. (2005). Recollecting Freud (A. Dundes, Ed.). Madison: The University of Wisconsin. (Original publicado em 1930).

Schepeler, E. (1990). The biographer's transference. Biography, 13(2), 111-129.

Schur, M. (1972). Freud: living and dying. New York: International Universities.

Sulloway, F. (1979). Freud: biologist of the mind. New york: Basic Books.

Whitebook, J. (2017). Freud: an intellectual biography. Cambridge: Cambridge University.

Wittels, F. (1924). Sigmund Freud: his personality, his teaching and his school (E. a. Paul, Trad.) New York: Dodd, Mead and Company. (Original publicado em 1924).

Young-Bruehl, E. (1998). Subject to biography: psychoanalysis, feminism, and writing women's lives. Cambridge: Harvard University. 


\section{Nota sobre os autores}

Marcus Vinicius Neto Silva é Psicólogo (Newton Paiva), especialista em Teoria Psicanalítica (UFMG), mestre em Estudos Psicanalíticos (UFMG), doutorando em Estudos Psicanalíticos (UFMG). E-mail: marcusviniciusnsilva@gmail.com

Guilherme Massara Rocha é Psicanalista, Prof. Adjunto do Departamento de Psicologia da UFMG. Membro da International Society of Philosophy and Psychoanalysis e da Fédération Européenne de Psychanalyse (FEDEPSY). E-mail: massaragr@gmail.com 